\title{
ATOMIC SAFETY AND LICENSING BOARDS: AN EXPERIMENT IN ADMINISTRATIVE DECISION MAKING ON SAFETY QUESTIONS
}

\author{
Arthur W. Murphy
}

The development of atomic energy in the United States has been characterized (with good reason) by a preoccupation with safety which is probably unique. This article will deal with only one part of the safety program, albeit a most important part-the effort to protect the public against injury from accidents at nuclear facilities (mainly reactors for the production of electric power). In that effort, the primary reliance is-as it must be-on those who build and operate reactors and on the regulatory staff of the Atomic Energy Commission. However, 'unless one is willing to place total reliance on industry and the staff, there must be a place in which their actions can be tested. And unless the public is to be denied the opportunity to participate, the test must be open to scrutiny. The job which has been given to the Atomic Safety and Licensing Boards is that of making a second-line review of reactor safety in the context of a public proceeding. The questions of major interest to readers of this symposium are what contribution to over-all safety the boards can make, given that assignment, and how the boards' procedures should be fashioned to accomplish their objective.

Given the special circumstances of reactor licensing, the implications of the experience of the boards for other fields are somewhat uncertain. It does seem, however, that the development of procedures by which the judgment of experts can be tested by nonexperts should be significant in all areas of safety, and indeed in all areas in which law, or society, must deal with the impact of science and technology. Moreover, the experience of the boards in trying to make such a test in a public proceeding should give some useful insights into the problem of making the public voice effectively heard where complex technology touches on the public interest. ${ }^{1}$

\section{The Background}

Although the licensing program is only fourteen years old-having come into being when the Atomic Energy Act of $1954^{2}$ (hereinafter, as amended, referred to as

- A.B. 1943, Harvard University; LL.B. 1948, Columbia University. Professor of Law, Columbia University. Member, Atomic Safety and Licensing Board, U.S. Atomic Energy Comm'n; Mcmber, N.Y. State Atomic and Space Development Authority.

${ }^{1}$ Of course, reactor licensing in general involves considerations common to all safety problems. Some of these considerations, such as how much risk is acceptable and at what cost safety should be purchased, are referred to below.

2 68 Stat. 919 (1954), as amended, 42 U.S.C. $\$ \$ 2011-2296$ (1964) [hereinafter cited as AEA]. 
"the Act") opened up the nuclear power field to private development-it has had a most complicated history. ${ }^{3}$ On three occasions, 1957, 1961, and 1967, it has received the concentrated attention of the Joint Committee on Atomic Energy (JCAE); twice the Atomic Energy Commission (AEC) ${ }^{4}$ has appointed special review panels; and in the normal course of events it has been under more or less constant scrutiny. The present stage of development is hardly likely to be the last. ${ }^{5}$ I will not try to give the history at length here, or even to describe the licensing procedure in detail, ${ }^{6}$ but some understanding of the procedure and its development is a necessary preliminary to the rest of the article and I will try briefly to give that background.

\section{A. The Licensing Process}

The licensing of a nuclear reactor is accomplished in two distinct phases: before the applicant can begin construction of the reactor he must receive a "construction permit"; after construction is completed he must apply for and receive an operating license. ${ }^{7}$ The application for a construction permit is not required to show a final design but only the type of reactor proposed to be built, the chief safety characteristics of the reactor, and the features of the proposed site pertinent to safety. ${ }^{8}$ A construction permit may be granted, if, inter alia, it is found that there is "reasonable assurance that the ... proposed facility can be constructed and operated at the proposed location without undue risk to the health and safety of the public."

The application is first evaluated by the AEC's Division of Reactor Licensing. This division, with a number of others, constitutes the so-called "separated staff" under the Director of Regulation. ${ }^{10}$ The job of the Division when it receives an application has been described as follows:

${ }^{3}$ An excellent, concise description of the development of the licensing program is contained in Cavers, Administering That Ounce of Prevention: New Drugs and Nuclear Reactors-II, 68 W. VA. L. Rev. 233 (1966). An exhaustive Bibliography on Regulation of Nuclear Powerplants, prepared by the Legislative Reference Service of the Library of Congress for the Joint Committee on Atomic Energy appears in Hearings on Licensing and Regulation of Nuclear Reactors Before the Joint Comm. on Atomic Energy, 9oth Cong., rst Sess., pt. 1, at 439 (1967) [hereinafter cited as 1967 JCAE Hearings].

"The term $A E C$ is used to refer to the agency as a whole. Where it is necessary to refer to the Commission as a separate body, as in the case of adjudication, the term Commission is used.

${ }^{5}$ On July 8, r968, the AEC announced plans for an "in-house" review of the regulatory program. AEC Press Release No. L-I59, July 8, 1968.

${ }^{\circ}$ For a detailed exposition of the licensing process, see Kingsley, The Licensing of Nuclear Power Reactors in the United States, 7 ATOMIC ENERGY L.J. 309 (1965). A simplified description prepared by the AEC for general public information is set forth in $1967 / C A E$ Hearings 283 .

${ }^{7}$ AEA $\S \mathrm{x} 85,42$ U.S.C. $\$ 2235$ ( 1964$)$. The two-stage licensing procedure was upheld in Power Reactor Dev. Co. v. Int'l Union of Elec. Workers, 367 U.S. 396 (Ig6I). The Court took the view that "issuance of a construction permit does not make automatic the later issuance of a license to operate." $3^{67}$ U.S. at $4 \mathrm{Ir}$.

8 The contents of the application for a construction permit are specified in Io C.F.R. $\$ 550.33-34$ (1968).

Io C.F.R. $\$ 50.35$ (a) (I968). (Emphasis added.)

${ }^{10}$ The "separation" of the regulatory staff stems from a reorganization of the AEC in $x 961$ at a time when the propriety of its being simultaneously the promoter and regulator of atomic energy was the 
The staff of the Division of Reactor Licensing evaluates the application, with the assistance of such other elements of the staff as may be appropriate.

Other agencies of the Federal government are usually invited to express their opinions on the project within their respective areas of expert knowledge. For example, the Geological Survey of the Department of the Interior may be called upon to review geology and hydrology; the Coast and Geodetic Survey of the Department of Commerce may furnish a study of seismicity of the area; and the Weather Bureau in the Department of Commerce (now incorporated with the Coast and Geodetic Survey and other units into the Environmental Sciences Administration) may be requested to make a report on meteorology. The staff may also call upon consultants, within or outside of the Government, to evaluate specific aspects of reactor safety.

It generally happens that the staff either finds the application lacking in adequate information in one or more respects, or differs with the applicant in the safety evaluation or some aspects of the application. It proceeds to attempt to resolve these differences by conferences with the applicant and by addressing one or more letters to the applicant, presenting the questions which it wishes to have answered. The responses to these questions generally take the form of amendments or supplements to the application, adding to or modifying the information in the original application. The submission of this additional information is followed by informal conferences between representatives of the applicant and the staff, at which differences are ironed out as far as possible.

....

The staff then files its "safety evaluation." This report analyzes the site from the point of view of location and surrounding population, meteorology, geology, hydrology, and seismicity. It evaluates the adequacy of the containment and the design of the reactor plant, including reactor physics, the design of the core and fuel, the control rod drive system and reactor vessel, the coolant system, and the control and instrumentation. It also considers the adequacy of auxiliary plant systems, including power supply, fuel handling and storage, waste disposal and others. It analyzes the proposed research and development programs, and evaluates the technical qualifications of the applicant. It analyzes potential accidents in order to determine possible initiating mechanisms, the effectiveness of protective design features, and the consequences of possible dispersion of radioactive material into the environment. Attached to the safety evaluation are the reports of any other Government agencies and private consultants whose views have been invited, and one or more reports of the Advisory Committee on Reactor Safeguards.11

In addition to review by the staff, all applications for construction permits are required, under existing law, to be submitted to the Advisory Committee on Reactor

subject of concentrated attention in a number of quarters. The nature and background of that problem and proposals for its solution are covered in detail in W. Berman \& $L$. Hydeman, The Atomic Eneroy Commission and Regulating Nuclear Facilities (r96r), and I Stafp of Joint Comm. on Atomic Energy, 87th Cong., ist Sess., Improving the AEC Regulatory Process (Comm. Print 196r) [hercinafter cited as JCAE STAFF Srody], including (as appendix 5) a study prepared by the AEC entitled The Regulatory Program of the Atomic Energy Commission. See also the articles cited in notes 38 and 45 infra.

${ }^{11}$ Kingsley, supra note 6, at 319-2r. The best and most informative description of how the staff goes about its job is the testimony of Dr. Peter A. Morris, Director of the Division of Reactor Licensing, in 1967 JCAE Hearings 192. 
Safeguards (ACRS). The ACRS, originally established by the AEC sua sponte, became a statutory body in $1957 .{ }^{12}$ It consists of fifteen members (serving on a parttime basis) representing the various disciplines involved in an evaluation of reactor safety. The ACRS reviews the application, consults with the applicant and the staff, and reports to the Commission its conclusion as to whether the proposed reactor "may be operated without undue risk to the public." The ACRS report ("the ACRS letter") is a part of the public record, but its meetings, conducted informally and without a transcript, are not open to the public. ${ }^{13}$ The report is conclusory in form although it may often specify areas of study which it believes must be looked into before operation. The staff takes the ACRS report into account in its own safety evaluation but need not come to the same conclusion. In practice the staff has disagreed with the ACRS only twice. In one case a construction permit was granted notwithstanding an adverse ACRS report; ${ }^{14}$ in the other, a permit was denied although the ACRS letter was favorable. ${ }^{15}$

The Act requires that a public hearing be held before the grant of a construction permit. $^{16}$ This hearing - which is mandated whether or not requested by any interested person-was originally held before a hearing examiner. In 1962 , as part of a general reshaping of the regulatory process, a new entity was authorized: ad hoc Safety and Licensing Boards consisting of two "technically qualified" members and one member "qualified in the conduct of administrative proceedings." Alt Although the use of a board, as opposed to a single hearing examiner, is optional with the Commission, all hearings are now conducted by boards. The members of each board are chosen from a panel of (at this time) nineteen "technically qualified" members and six "administrators." As will be discussed later in the article, the nature of the hearing depends on whether the proceeding is "contested" or "uncontested." In theory the contest may be between the staff, urging denial of the application, and the applicant. In practice, no applicant has yet persisted in his application over the objection of the staff, so that the opposition in "contested" hearings has been by members of the public who intervene to oppose the grant. The board

\footnotetext{
${ }^{12}$ AEA $\$ 29,42$ U.S.C. $\$ 2039$ ( 1964$)$, establishes and prescribes the makeup and duties of the ACRS. By AEA $\$ \times 82$ (b), 42 U.S.C. $\$ 2232$ (b) (1964), the ACRS is required to review each application for a construction permit or operating license for a power or test reactor. That section also requires that the ACRS report be made part of the public record.

${ }^{13}$ In describing the ACRS function, the Joint Committee Staff said,

"Since the function of the ACRS is to advise the Commission and not to make a formal decision (although its recommendations, especially if adverse, may well determine the final decision) the ACRS meetings are conducted informally, with no formal statements or record, and are not open to the public. Some applicants have characterized the meeting as resembling a Ph.D. dissertation examination."

I JCAE STAFF STUDY 2I. See note 68 infra and accompanying text.

${ }^{11}$ The Power Reactor case, supra note 7 , which arose before ACRS review was made mandatory in 1957 .

${ }^{15}$ The application of Pacific Gas \& Electric Co. to build a reactor at Bodega Bay, California.

${ }^{10}$ AEA $\$ 189,42$ U.S.C. $\$ 2239$ (1964).

${ }^{17}$ AEA $\$ \mathrm{IgI}, 42$ U.S.C. $\$ 224 \mathrm{I}(\mathrm{Ig} 64)$.
} 
decision is the decision of the Commission unless reviewed. It may be reviewed by the Commission on the appeal of any party or on the Commission's own motion. It is, of course, also subject to court review.

Between the start of construction and the beginning of operation, the staff evaluation is more or less continuous. Before an operating license is issued the ACRS must again pass upon the application. Since 1962 there has been no requirement for a hearing at the operating license stage, however, except on the request of a party. AEC regulation continues throughout the life of the reactor. ${ }^{18}$

This may seem an unnecessarily complicated, redundant, and in some respects irrational system. There are many who believe it is all three. It has evolved, however, in response to a number of circumstances unique to the particular situation which ought to be kept in mind in assessing the system. Before turning to the primary topic of the article, I would like to spend a little time discussing some of those special circumstances.

\section{B. Special Problems of Reactor Licensing}

Without doubt the most singular aspect of the problem of reactor safety, and one which colors our whole approach to the subject, is the magnitude of the possible accident. A number of estimates of the possible consequences of an accident have been made. The most famous (or infamous), known as the Brookhaven Report, ${ }^{10}$ was made by staff members of the Brookhaven National Laboratory and others at the request of the JCAE at the time proposed nuclear indemnity legislation was under consideration. The report postulated that under the most pessimistic circumstances a reactor accident might kill 3400 people, injure 43,000, and cause damages of $\$ 7$ billion (primarily contamination of land areas). The chances of such an accident's occurring were regarded as "exceedingly small." In any event, as the report stresses, the particular numbers are meaningless except as indicating a range of possibilitics. ${ }^{20}$ The actual amount of damage caused by an accident would depend on an almost infinite number of variables.

Due in part at least to the potential for serious accidents, the approach of the

\footnotetext{
${ }^{18}$ Since my concern here is with the licensing process, I will not attempt to deal with postlicensing supervision. This is not to suggest, however, that what happens later is unimportant; indeed some observers believe that the critical period of regulation may well come after operation is licensed. Obviously, unless the safeguards incorporated in the design are maintained in good operating condition, they may fail when needed. Experience suggests that it may be difficult to persuade operating personnel to pay sufficient attention to systems designed to guard against accidents which they consider incrediblc. In the case of at least some of the nuclear accidents which have occurred, early warning systems have been ignored. Although the primary responsibility for resolution of this problem will be in the postlicensing period, boards have expressed interest in the applicants' proposed training programs.

${ }^{10}$ Atomic Energy Comm'n, Theoretical, Possibilities and Consequences op Mnjor Accidents in Large Nuclear Power Plants (Wash-740, 1957).

${ }^{20}$ In 1965 , AEC Chairman Seaborg reported that a subsequent study concluded that the chances of a major accident were even more remote but that the possible damages were substantially greatcr (because of increased reactor size). Hearings on Proposed Extension of AEC Indemnity Legislation Before the Subcomm. of Legislation of the Joint Comm. on Atomic Energy, 89th Cong., Ist Sess. 347-48 (1965).
} 
AEC to matters of safety has been different from that usually followed. ${ }^{21}$ Ordinarily the unregulated use of toxic materials has been permitted until accidents have demonstrated their toxicity or the public danger from their use. In the case of atomic energy the "burden of proof" has been put on those proposing its use. Perhaps as a result of this caution, the safety record of the nuclear industry has been remarkable. There have been very few reactor accidents of any kind and, in this country at least, no injury to members of the public. ${ }^{22}$ Notwithstanding this remarkable record, the effort continues to try to anticipate all hazards, both known and unknown. It seems doubtful that there ever has been an instance in which so much has been done to guard against accidents which are regarded as wholly improbable, although theoretically possible.

Another unique aspect is the size and expense of the installation being licensed; many of the proposed plants will cost over \$roo million and some over $\$ 200$ million. ${ }^{23}$ This factor has potentially great significance in terms of the applicant's willingness to accommodate to the wishes of the staff or the ACRS. ${ }^{24}$ It probably also means, as a practical matter, that once a reactor is built, both sides will be under considerable pressure not lightly to interfere with its operation. ${ }^{25}$

\section{The Nature of the Safety Decision}

Radioactivity can be dangerous, and the only way in which one can be absolutely sure that no damage is done is not to build reactors-a course of action which so far has been rejected. Granted then that some risk will be taken, how much will be tolerated? Logically this "policy" decision should precede the work of the regulatory staff, the ACRS, and the boards. The Act itself contains no guidance except the injunction in sections $\mathrm{rO}_{3}$ and ro4 that no license is to be issued to a person if in the opinion of the Commission the issuance "would be inimical to ... the health and safety of the public." ${ }^{\prime 26}$ The AEC regulations bearing on the problem

\footnotetext{
${ }^{21}$ This "upside down" approach to safety parallels the unusual development of atomic energy from government monopoly to regulated industry, an aspect of the development of the peacetime program discussed in Palfrey, A New Experiment in Government-Industry Relations, 56 Corum. L. REv. 367 (1956).

${ }^{22}$ A complete review of nuclear "incidents" through $196 \mathrm{I}$ is contained in Smets, Review of Nuclear Incidents, in Progress in Nuclear Energy, Series X, 3 LaW \& Administration 89 (J. Weinstein ed. I962).

${ }^{28}$ See, e.g., I5 NuClear Industry, Jan. I968, at Ir, and ${ }_{5}$ Nuclear INDUSTRY, May I968, at 22-24, for the estimated costs of proposed plants. These figures include the cost of the turbine and other equipment as well as the reactors themselves.

${ }^{24}$ But see the colloquy between Representative Hosmer of the JCAE and Dr. Morris, Director, Division of Reactor Licensing in 1967 JCAE Hearings 204, where Dr. Morris discounts the "fear and trembling" of applicants.

${ }^{20}$ The contention that the high cost of construction would make the issuance of an operating license automatic was central to the intervenors' argument in the Power Reactor case, supra note 7. In I963, the reactor involved in that case was licensed to operate at the nominal power level of I MWT, and in 1965 authority was granted to operate at a power level of $300 \mathrm{MWT}$. The reactor has been shut down since October 1966 because of a fuel meltdown. For a discussion of that accident, see Green, Safety Determinations in Nuclear Power Licensing: $A$ Critical View, 43 Notre Dame Law. 633, 650-5I (I968).

${ }^{20} \mathrm{AEA} \S \S \mathrm{r03}, 104,42$ U.S.C. $\$ \$ 2133,2134$. (Emphasis added.)
} 
are contained in part 100, "Reactor Site Criteria." Part roo contains the general admonition that:

It is expected that reactors will reflect through their design, construction and operation an extremely low probability for accidents that could result in release of significant quantities of radioactive fission products. In addition, the site location and the engineered features included as safeguards against the hazardous conscquences of an accident, should one occur, should insure a low risk of public exposure. $^{27}$

After this admonition part roo goes on to list a number of specific factors to be taken into account, including population density and such physical characteristics of the site as seismology, meteorology, and so forth. Population density is a critical element. For example, the regulations contemplate an "exclusion area" around the reactor, and a zone around the exclusion area in which the population density is sufficiently low that the residents could be evacuated or otherwise protected in case of a serious accident. It is expressly recognized that all of these criteria (except possibly for that requiring the site to be no closer than a quarter mile from an active earthquake fault) are guidelines rather than prerequisites to licensing, and, indeed, the regulations state specifically that, notwithstanding unfavorable physical characteristics, a site may be acceptable "if the design of the facility includes appropriate and adequate compensating engineering safeguards." ${ }^{28}$ It is this authorization to rely on engineering safeguards that opens the way to urban siting even within the present criteria.

Obviously these regulations do not answer the question as to what risk will be tolerated-except to indicate that the tolerance should be low. Given this general "standard," the regulation might have proceeded to quantify the risk in terms of the magnitude of exposure and the likelihood of releases of radioactive materials. So far this has not been done. Instead, the practice has grown up of measuring the safety of design by its ability to withstand an accident of postulated intensity. The genesis of this practice is, again, in part 10o. For purposes of calculating the necessary "exclusion area," "low population zone," and "population center distance," the applicant is required to calculate the exposure from an accident involving a meltdown of the core and substantial fission product release. The accident postulated is directed to be one resulting in potential hazards "not exceeded by those from any accident considered credible."29 The regulation does not elaborate any criteria for the finding of credibility, and it is obviously an imprecise standard..$^{30}$

\footnotetext{
${ }^{37}$ Io C.F.R. ई 100.10 (Ig68).

${ }^{28} I d$.

${ }^{29}$ ro C.F.R. I00.Ir (I968).

${ }^{80}$ In his testimony before the JCAE in 1967 , Dr. Peter A. Morris, Director of the Division of Reactor Licensing, discussed the replacement of the "maximum credible accident" concept with that of a "design basis accident," which is in turn "hardly credible." 1967 JCAE Hearings 200. With all deference, this reformulation does not seem to be much of an improvement.
} 
The inadequacy of a formulation in terms of credibility has led to increased interest in quantification of risk: ${ }^{31}$

The building of a reactor implies the acceptance of some finite degree of risk. No engineering plant and no structure is entirely risk free, and there is no logical way of differentiating between credible and incredible accidents. The incredible is often made up of a combination of very ordinary events-for example, the breakdown or deterioration that occurs in normal plants and their measuring instruments -and the credible may be exceedingly improbable. The logical way of dealing with this situation is to seek to assess the whole spectrum of risks in a quantityrelated manner and thus provide for the choice of sites for nuclear power stations. ${ }^{32}$

One important difficulty with using calculations of accident probabilities is that there may be no reliable figures available on many aspects of the calculation. Where the pieces used are standard items, such as pumps, experience in non-nuclear contexts can be utilized, but in many instances the records of such uses are not sufficiently reliable. Where actual reactor data is required, there may simply not be enough data of any kind. Indeed the kind of accident postulated in the Brookhaven report is probably sufficiently remote that we will never acquire enough experience on which to base a meaningful statistical forecast of its probability. ${ }^{33}$

Certainly one difficulty with using calculated probabilities is the public relations problem of the AEC (and the Congress). Although the public seems willing to accept large risks unprotestingly, as for example in automobile travel, the statistical risks they are taking have not ordinarily been articulated. As a public relations matter it is probably more palatable to talk about the Brookhaven report accident as incredible than to place a figure of, say, one chance in $10^{10}$ on the risk. One can imagine the political dialogue which might follow a Commission decision that a one in a billion chance of making part of the Borough of Queens uninhabitable for a while was an acceptable risk. With the apparent growing interest of the public in safety, it is to be hoped that there will develop a willingness to think in terms of relative safety; in any event, it does seem time to begin to gather as much information as possible. ${ }^{34}$

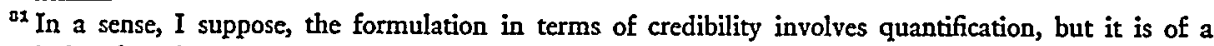
rhetorical rather than a mathematical nature.

${ }^{32}$ Farmer, Reactor Safety and Siting: A Proposed Risk Criterion, 8 NuCLEAR SAFETY 539 (1967). The quoted language is an abstract of the article.

${ }^{33}$ The Broolshaven Report, supra note I9, estimated the probability of a reactor accident involving a "major release" of radioactive materials as between $x / 100,000$ and $I / I$ billion per year per reactor. Assuming a maximum number of reactors in this country at between 300 and 3000 the statistical chances of such an accident could be pretty low.

${ }^{34}$ 'The closely related question of how much the public is willing to pay for safety bas been muted in the case of reactors, where, to date, questions of cost seem to have been subordinated to considerations of safety per se. See note 74 infra. There have been rumblings of unhappiness, however, particularly with respect to the problem of "back-fitting"- the imposition of new safety technology on previously licensed reactors-which can be very expensive. The requirement of extensive "back-fitting" can also make a mockery of the original economic choice between nuclear and conventional power.
} 
II

\section{The Development of the Boards and Their Function}

\section{A. The Requirement of and Function of a Hearing}

It is impossible to separate the development of the Atomic Safety and Licensing Boards from the requirement of a hearing. Prior to 1957 , a hearing was required only if requested by an interested party; in 1957, a hearing was made mandatory both as to construction permits and operating licenses ${ }^{35}$ whether or not requested by an interested party.

Considering the unusual nature of the requirement of a hearing in the absence of a contest, there was surprisingly little discussion of what, precisely, the hearing was supposed to accomplish. In part it seems to have been felt that, given the newness of the power program, members of the public might be insufficiently aware of their interest to respond to a notice of intention to license, so that a hearing was necessary to make them aware that their interests were affected. ${ }^{36}$ The dominant objective seems to have been to ensure that important AEC decisions would be made publicly. ${ }^{37}$

Although the statute did not specify any particular kind of hearing, the AEC followed the traditional practice of a "trial-type" hearing before a hearing examiner. Moreover, the process was judicialized to the extent of "isolating the hearing examiner and even the Commission itself from its own technical staff."

\footnotetext{
${ }^{35}$ Requests for modification of construction permits and operating licenses were also the occasion for hearings. See W. Berman \& L. Hydeman, supta note io, at 130-34.

${ }^{38}$ The requirement of a hearing in uncontested cases was recommended in a JCAE staff study in 1957. A brief discussion of the underlying reasons is given in STAFF of JoINT CoMm. ON ATOMro Energy, 85 Cong., ist Sess., A Study of aEC Procedures and Organization in the Licensing of REACTOR Facilities 17-25 (Comm. Print 1957). The genesis of the recommendation and the obscurity of the reasons for which it was adopted are commented on in W. BERMan \& L. Hydeman, supra note Io, at $84-87$.

${ }^{37}$ See the Statement by Senator Anderson, the sponsor of the proposal and Vice-Chairman of the JCAE:

"When the Atomic Energy Act was amended 3 years ago, I made the following statement on the floor of the Senate on July I4, I954, expressing my opinion as to the advisability of public hearings on reactor license applications:

". . . But because I feel so strongly that nuclear energy is probably the most important thing we are dealing with in our industrial life today, I wish to be sure that the Commission has to do its business out of doors, so to speak, where everyone can see it.

"Although I have no doubt about the ability and integrity of the members of the Commission, I simply wish to be sure they have to move where everyone can see every step they take; and if they are to grant a license in this very important field, where monopoly could so casily be possible, I think a hearing should be required and a formal record should be made regarding all aspects, including the public aspects."

Hearings on Governmental Indemnity and Reactor Safety Before the Joint Comm. on Atomic Energy, 85th Cong., Ist Sess. 7 (1957). And see S. Rep. No. 296, 85th Cong., rst Cess. 12 (1957): "The Joint Committee concluded that full, free, and frank discussion in public of the hazards involved in any particular reactor would seem to be the most certain way of assuring that the reactors will indecd be safe and that the public will be fully apprized of this fact."

${ }^{\text {ss }}$ Cavers, Administrative Decision Making in Nuclear Facilities Licensing, 110 U. PA. L. REv. 330 (1962).
} 
else such a hearing might accomplish, ${ }^{39}$ since the hearing examiner was legally rather than technically trained, it could not constitute a meaningful review of safety factors. There was fairly widespread dissatisfaction with the licensing process established in 1957, and in I96r a new review was undertaken by the JCAE staff. Much of the discussion at that time focused on whether the regulatory and promotional function of the AEC should be split into separate agencies, a matter with which I will not deal, ${ }^{40}$ and on the wastefulness of the process, with which this article is only secondarily concerned. ${ }^{41}$

On the question of the hearing, there was general agreement that a single hearing, at the construction permit stage, was enough. ${ }^{42}$ As to the purpose of the hearing, there was sharp disagreement between the AEC and, among others, the JCAE staff. The AEC position was that things were all right as they were; specifically the AEC opposed the institution of a technical review after the staff and ACRS had completed their work. ${ }^{43}$ The JCAE staff strongly urged a technical review by a safety and licensing board which would include two technically trained people and advocated that the review be within the framework of a hearing (of a somewhat less judicialized type than had been the practice). ${ }^{44}$ The question of the form of hearing was eloquently debated by Professors David F. Cavers and Kenneth Culp Davis in a series of articles in the January I 962 University of Pennsylvania Law Review. ${ }^{45}$ At the risk of oversimplifying their positions, it seems fair

\footnotetext{
30 "It has been urged that a hearing before an examiner has several values: that it provides an orderly public record of the grounds on which the staff approved the reactor, that it puts pressure on the applicant and the staff to do their homework, and that it provides an opportunity for intervention by public or public spirited bodies." Id. at 346 (citing I JCAE StafF Study 49 ).

10 The creation of a separate regulatory agency is still being urged. See Green, supra note 25, at 655. See also the statement of Commissioner Ramey, reported in 15 Nuchear INDUSTRY, Sept. 1968, at 8. Whatever its merits such an agency would not avoid the problems of decision making discussed here.

11 See the studies cited in note ro supra. A concise review of these studies is given in Cavers, stupra note 38 , at $332-34$.

${ }^{12}$ Of course a hearing will be held at the operating license stage if requested by an interested party. 42 U.S.C. $\$ 2239$ (a) (1964).

"See 2 JCAE STAFF STUDY 4I8: "The function of the hearing examiner is to receive, marshal, and cvaluate, not to supplement or qualify, the evidence." The narrow view of the function of the hearing urged by the AEC is best illustrated by the following extraordinary statement: "The question entrusted by Congress to the Commission and by the Commission to the hearing examiner is whether a specific reactor ought to be allowed to operate in view of the policies laid down by the act as implemented in the regulations. The resolution of that question has no relation to the technical skills of the person or persons constituting the tribunal." Id.

"I JCAE STAFF STUDy 5-6, 65-75. The staff specifically took issue with the AEC's narrow view of the hearing:

"The Commission seems satisfied to provide a procedure for formal review before a lawyer, the hearing examiner, with formal or informal review by the Commission. The emphasis is thus placed on procedural fairness and a suitable record for judicial review, a carryover from agencies in which-unlike the AEC-contested cases are the rule. But where the safety of many people and the future of a potentially great industry are at stake, a reactor licensing review that reaches the wrong result is not satisfactory simply because it satisfies due process."

Id. at 67 .

${ }^{4}$ See Cavers, supra note 38, followed by Davis, Nuclear Facilities Licensing: Another View, r1o U. PA. L. REv. $37 \mathrm{I}$ (I962), followed by Cavers, Nuclear Facilities Licensing: A Word More, id. at 389 .
} 
to say that Professor Cavers felt that a hearing was essential to subject the decision to public scrutiny, whereas Professor Davis felt that in the absence of a contest any trial-type hearing was an absurdity. He advocated an "executive"-type review in place of the "judicial" scrutiny, and would have had the procedures worked out by "management engineers, not lawyers."

Although it did not adopt all of the suggestions of the JCAE staff, ${ }^{47}$ Congress opted for a technical review and for a hearing. It emphasized, however, that the hearing should be informal and that the judicialization of prior practice should be abandoned. ${ }^{48}$ It gave some specific directions as to procedure-for example, that in uncontested proceedings, the ex parte rules should be relaxed to permit board members to consult with the AEC staff-but directed that the boards should be experimental.

The decision to have the mandatory hearing at the construction permit stage, rather than before the operating license is issued, may need a note of explanation. The cost of a nuclear plant is such that, as a practical matter, the critical stage in the licensing process is the construction permit stage. Before he builds the reactor, the prospective licensee must know at least that a reactor of the general type proposed will be permitted at the proposed site. So too, if the public is to be given any voice, it must have an opportunity to object before that assurance is given.

Sensible as the timing of the hearing is, it does complicate the job of the boards. Reactor technology is in its relative infancy, which means that there will inevitably be design changes between the time the construction permit is granted and the time operation is licensed. As a result, the board must evaluate an incomplete design. In time, as reactor technology stabilizes, this problem should be less serious, but the need for a final decision on the construction permit has troubled many board members. ${ }^{49}$

\footnotetext{
${ }^{15}$ IYo U. PA. L. REv. at 374. To the extent that public education was to be a function of the hearing, Professor Davis proposed a hearing in the nature of a press conference in the locality with an opportunity for questions. Id. at 373-74.

${ }^{47}$ For example, it rejected the permanent board in favor of an ad hoc board and made the use of a board optional.

${ }^{8}$ S. REP. No. 1677,87 th Cong., 2d Sess. (1962). The Committee said, "The Atomic Safety and Licensing Board is conceived as a flexible experiment in new administrative law techniques" (id. at 5), and "[I]t is expressly stated here that the Committee encourages the Commission to use informal procedures to the maximum extent permitted by the Administrative Procedure Act." Id. at 6. See also in this respect, I JCAE STAFF STUDY 72.

${ }^{10}$ As a logical matter, if the construction permit is granted on the basis of certain assumptions as to information being supplied in the future, and there is no assurance of an independent review of whether those assumptions prove to be true, the most important decision as to safety may be made by the staff and not by the board. The only complete solution to this problem would be to let the boards retain jurisdiction to see that the assumptions turn out to be true. This solution was adopted by the board in the Jersey Central Power \& Light Co., 2 A.E.C. 446 (I964), but the present regulations, 10 C.F.R. $\$ 2.717$ (a) (1968), make clear that the board does not retain jurisdiction after the permit is granted, although if a hearing is ordered at the operating license stage the Commission has stated that it will "attempt" to use the same board. Io C.F.R. pt. 2, app. A, para. IV (Ig68). As a practical matter, the problem is managed by the insistence on a fairly complete "reference design" at the construction permit stage. The boards have generally tended to follow the lead of the board in Niagara Mohawk
} 
The critical choice which was made was, of course, to add another technical review to those of the staff and the ACRS. It is hard to know exactly what underlay this decision, and I will not try to analyze it here. Undoubtedly a number of factors played a part; the general uneasiness with the Commission's dual role as a promoter and regulator of nuclear power was surely a factor, as was the feeling-mentioned above-that the public was insufficiently informed to play a significant role by intervention. The congressional wish to oversee the work of the staff is of course understandable, but to a considerable extent that function was already being fulfilled by the ACRS. Whatever the reason, the objective of having the boards make a technical review seems clear enough. What was not clear was how they were supposed to go about it.

\section{B. The Regulations}

Although the boards have not, I think, wholly accepted the invitation to "dejudicialize" the proceeding, a good deal of progress has been made, and by now the conduct of the hearings has become fairly routine. At the hearing the chairman delivers a statement designed to explain the jurisdiction of the board, the possible interests of other federal or state agencies, and the proceedings in the regulatory agency taken to date. The staff and the applicant introduce, as a joint exhibit, the application and all amendments thereto. This exhibit plus the qualifications of witnesses, the applicant's "partial summary and safety analysis," and the staff's "safety evaluation" ordinarily constitute the record introduced at the hearing. There may be some examination of witnesses by the staff counsel, or one or two questions by the applicant, but as a rule both rest at that point. Usually the board will then spend a good deal of time asking questions of the staff and the applicant's witnesses designed to clarify points in the record, to pursue apparent inconsistencies, and the like. When the board has exhausted its questions the typical hearing is terminated. ${ }^{50}$

The difficult problems have, not unexpectedly, centered about the scope of the technical review. In the beginning the boards were required to make findings as to whether-

(I) The applicant has described the proposed design of the facility, including, but not limited to, the principal architectural and engineering criteria for the design, and has identified the major features or components incorporated therein for the protection of the health and safety of the public;

Power Corp., 3 A.E.C. 5 (1965), which, although with misgivings, accepted the need for a final decision. The opinions in Niagara Mohawk and Jersey Central, as well as the action of the Commission with respect to this problem, are discussed in Cavers, supra note 3, at 248-50, 253.

${ }^{50}$ At some point in the hearing, representatives of various local and state agencies are given an opportunity to make statements; frequently there are limited appearances by people who want to express opposition to the reactor or to direct questions to the staff, or applicant, or board without taking on the job of intervening. Recently, at a number of hearings, attempts have been made to have the boards pass on such questions as "thermal pollution" or the right of other utilities to share in the electric production of the reactor, both of which questions presently are deemed to be outside the board's jurisdiction. See, e.g., the statement by AEC Commissioner Ramey in 1967 JCAE Hearings 25-26. 
(2) Such further technical or design information as may be required to complete the safety analysis and which can reasonably be left for later consideration, will be supplied in the final safety analysis report;

(3) Safety features or components, if any, whicl. require research and development have been described by the applicant and the applicant has identified, and there will be conducted, a research and development program reasonably designed to resolve any safety questions associated with such features and components; and

(4) On the basis of the foregoing, there is reasonable assurance that (i) such safety questions will be satisfactorily resolved at or before the latest date stated in the application for completion of construction of the proposed facility, and (ii) taking into consideration the site criteria contained in the regulations, the proposed facility can be constructed and operated at the proposed location without unduc risk to the health and safety of the public..1

The response of the boards to these instructions was varied. Some technical members were content with a fairly limited check of the staff and the applicant, while others felt that they could not make the required findings of safety without an extensive, independent check of the proposed facility.

The role of the boards might have been developed over a few years' time. However, in 1965 , a special panel was appointed to advise the Commission on, among other things, the decision-making process of the AEC regulatory program. This panel-known as the Mitchell Panel after its Chairman, former AEC General Counsel William Mitchell-made a number of far-reaching recommendations, including some concerning the function of the boards. ${ }^{52}$ The crucial recommendation was that the function of the board "be redefined specifically to recognize that a board cannot undertake, de novo, an independent technical review of the safety of a proposed facility." and contested cases but not to those issues actually in controversy in contested cases, as to which the Panel recognized that "the board may be called upon to make judgments of its own." 54

Following the Panel's report, the AEC amended its regulations governing uncontested proceedings, to dispense with the requirement that the board make findings and to define the board's role as that of deciding

\footnotetext{
51 10 C.F.R. $\$ 50.35$ (1959). In addition the boards were to find:

I. Whether the applicant is technically qualified to design and construct the proposed facility;

2. Whether the applicant is financially qualified to design and construct the proposed facility;

3. Whether the issuance of a permit for the construction of the facility will be inimical to the common defense and security or to the health and safety of the public. ro C.F.R. \$50.40 (1959).

02 The Panel report is set forth at $1967 / C A E$ Hearings 410. Among other things, the Panel recommended that ACRS review be made optional (at the option of ACRS) and that its attention be devoted chiefly to novel safety problems. Id. at $4 \mathrm{I} \%$.

${ }^{\mathrm{E}} \mathrm{Id}$. at $42 \mathrm{I}$.

E4 Id. at 422. But only "on those issues in controversy." As to issues not in controversy, the board "should not attempt to make an independent technical review of those issues alrcady cvaluated by the staff." Id. The shrinking of the board function and enlarging of dependence on the staff review has been questioned by Professor Cavers. See Cavers, supra note 3, at 250-55.
} 
... whether the application and the record of the proceeding contain sufficient information, and the review of the application by the Commission's regulatory staff has been adequate, to support the findings proposed to be made by the Director of Regulation and the issuance of the provisional construction permit proposed by the Director of Regulation. The board will not conduct a de novo evaluation of the application, but rather, will test the adequacy of the staff's review upon which are based the findings and form a provisional construction permit which the Director of Regulation proposes to issue..$^{55}$

In the contested proceeding, findings were still required on all "issues":

In considering those issues, however, the board will, as to matters not in controversy, be neither required nor expected to duplicate the review already performed by the Commission's regulatory staff and the ACRS; the board is authorized to rely upon the uncontroverted testimony of the regulatory staff and the applicant and the uncontroverted conclusions of the ACRS. ${ }^{56}$

The matter of primary concern underlying the Mitchell Panel report was (as they saw it) a tendency of some boards to view their function as that of a de novo review of the safety of the reactor, a procedure which the Panel felt was impractical, unnecessary, and so expensive as to threaten the development of nuclear energy. In responding, however, the Panel paid too little attention to the decision in the Ig62 legislation that there be a technical review-a decision made in full recognition of the fact that the work of the boards might, to some extent, be redundant.

Although there is some ambivalence in the discussion, the prevailing tenor of the Panel report is antipathetical to the idea of any safety review by the boards. How far along that road the AEC meant to go is hard to say. The necessity for a third safety check has not, of course, been universally conceded. By some, the boards have been tolerated as a hedge against the time when ACRS will be unable to review all reactors extensively. Others have accepted them because of the felt need for public review which could never be satisfied by the ACRS in its present form.

The AEC, however, still seems to think of the board's function as that of a tcehnical review, and the regulations' new formulation of that function should be regarded not as a retreat from the idea of such a review but as an effort to guide

Es Io C.F.R. pt. 2, app. A, para. III(g) (1968).

so so C.F.R. pt. 2, app. A, para. VI(d) (4) (1968). Throughout the remainder of the article I will focus on the uncontested proceeding and will not ordinarily treat specially the contested proceeding. It is true that the problems of the contested hearing are different in many ways, but in my view the underlying problem of how to achieve safety is common to both types of proceeding and they ought to be considered together. This is particularly true inasmuch as the only type of contested proceeding likely to be seen in the foreseeable future is one in which the contest is not between the applicant and the staff but between the applicant supported by the staff on the one hand and an intervening member of the public on the other. While there will undoubtedly be exceptions, it seems fairly predictable that in most cases the public interest will be no better represented by the intervener than it is in the uncontested proceeding. By and large, intervenors will have neither the funds nor the experience necessary to mount a full-scale attack on all aspects of reactor safety. The board must, of course, decide the issues contested, but that is not its only function; as in the uncontested proceedings, the objective is to test the safety of the reactor, and it will presumably do so in much the same way. 
the boards toward a feasible approach to carrying it out. Tested by that objective, the new formulation seems to me to be unsuccessful. Let us look first at the requirement that the board test the adequacy of the staff review. For one thing, it tends to turn the hearing into a contest between the board members and the staff, with a danger of creating bad relations between them and making a bad impression on the public.57 But, more importantly, it doesn't provide the board with a reliable standard of judgment. Suppose, for example, circumstances in which the board is dissatisfied with the staff review but because of its knowledge of reactor technology generally, and because of its independent examination of the applicant, it is satisfied that the reactor can be built and operated safely. Should it in such a case deny a construction permit? Or suppose it feels that the staff has done its job properly, but nevertheless feels-because of a different judgment on a close question of fact-that the safety of the reactor is insufficiently established. Should it grant a construction permit? The answer to both questions is, I suggest, "no." Yet in both cases the answer would be "yes" if the board did nothing more than test the adequacy of staff review.

The difficulties with the formulation stem from the fact that it is drawn from the not wholly analogous area of judicial review. The essence of a hearing de novo is that the reviewing agency takes a new, independent look at the facts. ${ }^{58}$ The denial of the intent to conduct a de novo review, coupled with the instruction to "test the adequacy of the staff review," suggests that the objective is the same as that of a reviewing court: to test the substantiality of the evidence. But implicit in the role of a reviewing court is the premise that, as to questions of fact, the trial court or agency under review has the "right" to be wrong." Only when the evidence is insubstantial or the decision is "clearly erroneous," or the like, can it be reversed. It is certainly not grounds for reversal that the reviewing court would have found otherwise on the same evidence. The relationship between the board and the staff is quite different, although the differences may be subtle in some respects. The board is interested not only in whether the conclusion of the staff is reasonable and fairly arrived at-but also in whether it is right. This critical difference in function would seem to inhere in the fact that the boards' primary raison d'être is the promotion of safety rather than the resolution of disputes.

This does not mean that the boards, any more than appellate courts, can, or should, try to redo everything done previously. There are many reasons why a

\footnotetext{
${ }^{87}$ Ironically, one concern of the Panel was to make sure that the hearings "emphasize the independent role which the staff has played in protecting the interests of the publie." 1967 JCAE Hearings 423.

${ }^{58}$ The term is used to describe both the situation in which the reviewing body relies on the record of the original trial (but makes its own judgment on that record) and that in which a completely new trial is held.

${ }^{50}$ On the scope of the review of the findings of administrative agencies, sec $4 \mathrm{~K}$. Davis, AduINistrative Law Treatise $\$$ 29.0I-.II (1958). The scope of review of the findings by courts sitting without juries is ordinarily also limited to cases of clear error although where the evidence is documentary some courts feel more free to make their own judgments. See F. Jasigs, Civiz Procrdune 528-30 (1965).
} 
review de novo is impractical and undesirable in this situation as well as in the case of a lawsuit. ${ }^{60}$ But that similarity should not obscure the fact that the concern of the boards is different from that of the appellate court.

The misleading effect of this formulation is not, I think, undone by the inclusion of the instruction to the boards that they test whether the application and the record "contain sufficient information ... to support the findings proposed to be made by the Director of Regulation and the issuance of the provisional construction permit." On the contrary, this seems to hark back to the days before 1962 when the hearing examiner's function was largely to see if there was evidence to support the findings.

Recent changes in the regulations-based on recommendations of a second advisory panel (the "little" Mitchell Panel) ${ }^{61}$-have added two new sentences to the instructions to boards, which read as follows:

In [testing the sufficiency of the evidence and the adequacy of staff review] the board is expected to be mindful of the fact that it is the applicant, not the regulatory staff, who is the proponent of the provisional construction permit. If the board believes that additional information is required in the technical presentation in such a case, it would be expected to request the applicant or staff to supplement the presentation, again being mindful of the fact that it is the applicant, not the regulatory staff, who is the proponent of the provisional construction permit. ${ }^{62}$

Although the reasons for this change are not specified, it seems obviously intended to forestall the boards' putting the burden of sustaining the application on the staft instead of the applicant. It should also serve as a reminder that the boards have a responsibility to make a technical review of the safety of the proposed reactor. It does not, however, give the boards any new insight as to the manner of making that review.

\section{III}

\section{The Boards in Operation}

Despite the criticisms implicit in the Mitchell Panel report, none of the boards has conceived its job as one of redoing the work of the regulatory staff. All have recognized that the primary responsibility for safety must be on the applicant and the staff; but to concede that much is only a first step on the road to fashioning a practicable and useful function for the boards.

\footnotetext{
${ }^{\circ 0}$ The regulatory process is already long and costly and the addition of a new full-scale review might well price nuclear power out of the market. It is also doubtful that enough competent personnel could be found to do the job. But even given the time, money, and personnel it would seem almost self-evident that the denial of responsibility to the staff (and for that matter the applicant) would eventuate in mediocre performance at the staff level with a possible loss of over-all competence. The primary reliance must be on good people at the operating level.

${ }^{02}$ The charter of this panel was to deal primarily with contested proceedings, but its report and the ensuing proposed regulation's cover uncontested proceedings as well. The report is set forth in 1967 JCAE Hearings 468-80.

${ }^{62} 33$ Fed. Reg. 8589 (1968). The new regulations became effective on July 12, 1968.
} 
The best description of how the boards have operated was given to the JCAE by Mr. Warren Nyer, Vice-Chairman of the Safety and Licensing Panel:03

While the individual board members differ in technique and each case is different from the others, generally the boards follow a pattern I will describe. The available information is examined by the board to provide answers to two questions. Firstly, for the case under consideration, do the positions of the staff and applicant rest on a consideration of the appropriate set of circumstances or has something been overlooked? While the likelihood that the board will contribute something new or find that something has been overlooked is not great, in any event this is the first step in a board member's evaluation process. Secondly, when the board in effect accepts that the pertinent topics have been identified, the board must then evaluate the treatment of these topics in terms of board members' personal knowledge and the presentations to the board.

The initiative in the foregoing basically rests with the applicant and the staff so that the testing in these steps is primarily an evaluation of the presented material. Testing in the sense I believe used in the question is accomplished by the board taking the initiative in probing staff and applicant to develop additional information for the record, to determine the degree of acquaintance and understanding of the staff and applicant with the presented material, and to spot check their performance in detail for some items.

An example of this type of testing on a broad level would be the consideration given to plans for development or engineering work not completed at the time of the hearing. The boards have probed both applicant and staff as to completeness of intentions, particularly with respect to contingency provisions in the event that expected results do not in fact materialize. Boards have asked for a delineation of the alternatives, and thereby have tested the sufficiency and adequacy with regard to overall planning. On a more detailed level, questioning has taken place with regard to details of plans for testing containments, the criteria established for containments, and the relation of expected performance to the safety of the plant. On occasion detailed questioning takes place on the design of a particular component such as a pump or control element to test the participants on their knowledge and understanding of the proposed designs and the safety-significance of design features. Such questioning, while detailed in nature, and providing information sometimes readily available in the documents in the board's possession, is intended to elicit a demonstration of a desirable depth of understanding of the design by the participants. In demonstrating for the board and the public such understanding, both applicant and staff support the sufficiency of information and adequacy of review. ${ }^{64}$

The review which Mr. Nyer describes is designed, essentially, to spot-check the work of the applicant and the staff. The areas checked tend to vary with the type of reactor and the interests of the particular board members. Where the reactor

\footnotetext{
${ }^{03}$ In 1967 the AEC made a major contribution to the functioning of the boards by appointment of a permanent chairman and vice-chairman of the panel with an executive secretary and supporting staff. The objectives of this move are described in AEC press releases set forth at 1967 JCAE Hearings 433-35.

${ }^{6} \mathrm{Id}$. at $159-60$. As Mr. Nyer points out, there is a considerable variety of approach among the panel members.
} 
involves a departure from previous practice, as, for example, the field fabrication of the pressure vessel, questions are apt to relate to the new feature. Otherwise, they are apt to relate to areas within the special competence of the board members which are thought to pose safety problems. Since the technical members of the panel represent a number of different specialties, different lines of questioning are apt to be followed in different cases, but the objective is generally the same: to test the applicant's and the staff's understanding of and handling of specific problems. The extent of questioning varies greatly with the individual board members and, of course, with the adequacy of the responses of the staff and applicant to the questions. When the initial responses are satisfactory, the board's questioning is apt to be brief. When they are not, the boards frequently engage in extended examination.

This approach by the boards seems to be patterned, more or less consciously, on the conduct of an executive or supervisor. It reflects the feeling that-apart from its public information function-about all the hearing can accomplish is to make the staff and the applicant do their homework. While there can be no serious doubt that the healthy influence of a prospective review on the staff or applicant is a major value of the hearing, ${ }^{65}$ there is some question in my mind as to whether the easy analogy to the "executive-type" review is wholly appropriate. The judgment of a supervisor about a subordinate's work will depend, I would suppose, to a great extent on his estimate of the subordinate's capability-an estimate formed over a period of time. It is true that, given the small number of manufacturers and a relatively stable staff, boards do have an opportunity to become familiar with the personnel of the applicants ${ }^{68}$ and the staff, but they cannot, and I think should not, ever have the same relationship to either as an executive to his employees.

Another question raised by this approach is whether, even conceding that the major reliance must be placed on the staff and the applicant, something more by way of a technical review is not possible and desirable at the board level. Should the board, for example, ever retain independent consultants to make independent tests of a particular matter? If so, what would the criteria be for determining when an independent review should be made? The problem is not, of course, unique to the boards. Reviewing agencies can rarely duplicate the work of the people subject to their supervision. Even if time would permit, ${ }^{67}$ in a complex technological field the reviewing agency is not likely to have expertise in all aspects of the

\footnotetext{
${ }^{05} \mathrm{See}$, in this connection, Cavers, stpra note 38 , at 355 : "The main value of this is calling forth the best efforts of the participants, in confronting them with the need to check back over the data, their theories, and the reasoning that supports their case." A similar argument can be made that the main value of the staff review is the stimulation of scientists and engineers engaged in the project. See Kennedy \& Heimann, The AEC Regulatory Process, in 2 JCAE StafF Study 563.

${ }^{B a}$ To date, the major burden of supporting the application has been on the personnel of the reactor manufacturer, and the great bulk of reactors for which construction permits have been granted are being built by two manufacturers.

or See note 60 supra.
} 
field which matches that of the manufacturer. This is true, it should be noted, of the regulatory staff itself, which does not and cannot duplicate the work of the applicant. The staff can and should bring to the job a different perspective; it should, for example, be alert to those areas in which the manufacturer may want to trade safety for efficiency. But its job is, as the board's, one of review, and if it is ever to get the job done, it too must select parts of the work for analysis. The board, because it is not the first line of defense, must be content with a narrower selection.

The job of working out a proper role for the boards is somewhat complicated by the existence of the ACRS. ${ }^{68}$ The fact of ACRS review has influenced both the role assigned to the boards and-or so it seems to me-the way in which board members have approached their job. The extent of this influence is hard to assess. In a particular case the board knows only what appears in the ACRS letter, a document phrased in terms of great generality. In an uncontested proceeding the ACRS letter plays no formal part, ${ }^{69}$ although it must, by statute, be part of the record for the purposes of showing compliance with the requirement of ACRS review. Sometimes it is used as a frame of reference for testing the staff review, perhaps by asking the staff how they have responded to questions raised by ACRS. But the impact is more than the formal effect of the letter in a particular proceeding. Most of the board members are familiar with the ACRS work-a number of board members have served on the ACRS-and it is on that familiarity that they rely. Certainly to the extent that the board's function is to test the adequacy of staff review, the boards are made more comfortable in spot-checking by the knowledge that the ACRS has conducted its own review. Probably the boards more easily accept the fact that theirs may be the last hearing because the staff remains subject to ACRS review. The role of the ACRS has been much discussed of late; the Commission has recommended that the ACRS review be discretionary in some cases, ${ }^{70}$ and this change, as a minimum, seems likely in the near future. The effect on board procedures of a change in ACRS function remains to be seen.

\footnotetext{
${ }^{68}$ The role of the ACRS in the development of atomic power is worthy of separate treatment, a treatment which, it is hoped, it will be given some day. A good picture of the history, philosophy, and method of operation of the ACRS is given in the statements of Nunzio J. Palladino and David Okrent in $7967 J C A E$ Hearings 84 , and in the colloquy with members of the JCAE at the time of their testimony. For a general description of the ACRS operation, see Kingsley, supra note 6, at 322-24, and 2 JCAE STArp STUDY $139-4 \mathrm{r}$.

${ }^{60}$ The regulations, Io C.F.R. pt. 2, app. A, para. III(g)(I) (I968), say that in the uncontested hearing the board may rely on the "uncontroverted conclusions of the ACRS." In the ordinary case the only conclusions-if they be such-reached by the ACRS pertain to the ultimate issue, i.e., that "the reactor can be constructed at the proposed site with reasonable assurance that it can be operated without undue risk to the health and safety of the public." It can hardly be intended that the board rely on that "conclusion."

${ }^{70}$ I5 NuClear INDUSTRY, April I968, at 7. Discretionary review, at the option of ACRS, was recommended by the Mitchell Panel. 2967 JCAE Hearings 418. A more searching inquiry into the ACRS has been suggested by Rep. Craig Hosmer, the ranking Republican House member of the JCAE. "I cannot help but wonder if ACRS has outlived its usefulness-if it now serves less as a protective boon than it does as an anachronistic burden." I5 NucLear Industry, June 1968, at 54-55.
} 


\section{Some Possible Modifications}

\section{A. The Board's Functions}

One specific suggestion that has been made-by Professor Cavers in 1962 -is to pattern the board review on that of the ACRS:

Perhaps the best analogue to the Atomic Safety and Licensing Board that I have envisaged is none other than the ACRS as it now operates. The main differences between the proposed Board's review as I see it and the ACRS review as it is now conducted are these: First, the Board's review proceedings would be public. Second, the Board's review would tend to be somewhat more comprehensive and less of a spot check, though certainly the Board should not reexamine every point covered in the staff's investigation. ${ }^{71}$

Professor Cavers' suggestion was made in the context of his proposal for a pemanent safety and licensing board rather than the ad hoc boards which Congress created. ${ }^{72}$ One consequence of the use of ad hoc boards is that the review must be less comprehensive than the ACRS review and more of a spot check, but the ACRS procedure warrants careful attention. A major difficulty may be to adjust the ACRS mode of operation to the need for a public proceeding. Some of the easy exchange of views of the "Ph.D. examination" will inevitably be lost, and there is a real danger that the need to state positions publicly will tend to make them more inflexible.

One thing which could usefully be done is to make sure that the record as it is introduced is framed in such a way as to facilitate the work of the board. Since the board will ordinarily be reviewing the processes of the applicant and staff, it would seem most useful for the record to set forth the questions which the applicant

\footnotetext{
${ }^{71}$ Cavers, supra note 38, at 359-60. Professor Cavers argued strongly that the boards should conduct a technical review:

"The licensing review proceeding constitutes an examination into a complex set of factsincluding theories and expert opinions-in order to appraise the conclusions reached by the AEC staff which has conducted the basic investigation and by the AEC's adviser, the ACRS. This review is not designed to resolve disputes but to check judgments-judgments on interrelated scientific, technological, and policy questions. Yet in the process of checking these judgments, the examining board may, through its process of study and questioning, find itself growing doubtful of the factual foundations of the conclusions reached by the staff at certain points, and it may call for more evidence, possibly for new research and experimentation. Its role should not be conceived as that of an umpire in an adversary process. Rather, its role should be much more affrmative, and its procedure more flexible and less formal."

Id. at 359 .

72 The eventual establishment of a permanent board was contemplated by the JCAE in 1962. S. REP. No. 1677 , supra note 48 , at 5 . Such a board may be the way of the future. See the speech of Commissioner Ramey, Looking Ahead at the AEC Regulatory Programs, in 1967 JCAE Hearings 454, 46x. And see Cavers, supra note 3, at 254. A permanent board would have some important advantages over the ad hoc boards. Where, for example, the reactor is one of a series of similar reactors the ad hoc boards have had some difficulty in deciding to what extent the proceedings on earlier reactors in the series (on which they did not sit) should be relied on-a difficulty which would be obviated by a permanent board. A permanent board would, however, sacrifice the strength of the different specialties represented by the ad hoc consultants. A permanent board would not, in any event, avoid the questions as to function and hearing format discussed in this article.
} 
thought important, how it went about answering them, and why it thought the answers were acceptable. So too, the staff should concentrate on setting forth those aspects which caused it concern: what it discussed with the applicant; where its computations were different; why; why it accepted the applicant's answer; why it insisted on certain changes, and so forth.

To so prepare the record would reflect the fact that most of the time the board will be testing the process rather than the specific results. In addition, including such material should permit the board to get behind the surface agreement of the staff and applicant and at least see if any disagreements are being glossed over. The ability to get behind the surface agreement could be most important. For example, the predominant response of the ACRS, the staff, and perhaps the industry to safety problems has been the insistence on back-up systems: if it is vital that a particular system work, and if a component of that system is dependent on power from a particular source, one obvious answer ${ }^{73}$ is to provide an alternative source of power-say, a diesel motor-or even two. Apart from the question of cost, which may be considerable, ${ }^{74}$ there is at least some feeling that the insistence on "redundancy" may be reaching the point of diminishing returns and that care must be taken that some added safeguards may not prove to detract from over-all safety. ${ }^{75}$ For the staff, the insistence on an added safeguard is an easy way of making its record look good-when a board later looks into the adequacy of its review. As noted above, there are strong pressures on the applicant to "go along" with the staff request even though in its judgment the safeguard is unnecessary. ${ }^{70}$ Unless the board knows of the disagreement, it may not look into the question.

\section{B. The Hearing Format}

Even without the requirement of a public hearing, the identification of the proper function for the board, and the best way to perform that function, would be difficult. ${ }^{77}$ The need to do the job in a public hearing complicates the problem a great

\footnotetext{
${ }^{78}$ The general assumption that cost is the only problem is expressed in Grecn, stipra note 25, at 655: "In every instance, the risk can be reduced through incorporation of additional, though costly enginecring safeguards."

"The proposed Fort St. Vrain reactor (a gas-cooled reactor) in Colorado contemplates the use of a pre-stressed concrete pressure vessel without the containment shell which has been customary in water reactors. Although the ACRS approved the design, one member took the position that a containment shell should be required as a safeguard against leakage of the pressure vessel. The cost of such containment was estimated at $\$ 2$ million to $\$ 5$ million:

${ }^{75}$ At the 1967 Hearings the question was raised with Dr. Clifford Beck, Deputy Director of Regulation, and then ACRS Chairman Nunzio J. Palladino. Both felt that at present this was not a problem. 1967 JCAE Hearings 75-76 (Beck), I22 (Palladino).

${ }^{76}$ The tendency of applicants to accede to staff requests may also have the effect of inflating costs to the public. While nuclear power generation must compete on a cost basis with conventional generating techniques, the utility has the right to include in its rate base whatever investment it reasonably makes in generating facilities. It seems unlikely that a safety feature required by the AEC would not be decmed a reasonable investment. Thus, the separation of the safety function from the rate-setting function creates a danger that the public may be required to pay for "gold-plating."

${ }^{77}$ Undoubtedly, the role of the boards will, and should, vary with the state of the art, and the
} 
deal. As noted earlier, just the fact of being on the record will undoubtedly tend to harden positions and make the exchange of views less free. And although the processes of the boards are considerably less formal than a lawsuit-for example, the use of a round table discussion among all witnesses rather than direct and crossexamination of witnesses individually-the space and time limits of the hearing are more restrictive than the usual method of "executive" scrutiny.

Perhaps the greatest difficulty will be the adjustment of the methods of scientific inquiry to the needs of a public record or-where the proceeding is contested-to the requirements of due process. So far the response to this problem has been along the traditional lines of "official notice." The AEC regulations prescribing the extent to which official notice may be taken permit official notice "of any fact of which judicial notice might be taken by a court of the United States and of any technical or scientific fact within the knowledge of the Commission as an expert body. ..."79 However, despite this broad provision, the regulations seem to suggest that official notice is only appropriate where the "facts do not have to be 'proved' since they are matters of common knowledge." Given the ambiguity of the regulations and the general murkiness of what Professor Davis has called the "much misunderstood"11 concept of official notice, these provisions might not inhibit too much the technical members whose habits of acquiring information are deeply ingrained.

The provisions on ex parte communications promise more trouble, however. Although in the uncontested hearing, ${ }^{82}$ the rules permit access to the staff and other members of the panel, they forbid such access in the contested hearing. ${ }^{83}$ These rules seem a step in the wrong direction. They can produce the result that a board with, say, a metallurgist as one of its technical members can take official notice of a fact within his field of interest but that same information cannot be given to a fellow panel member in another case; and they tend to neutralize the advantage of the panel system in providing access to a number of different specialities.

Perhaps most importantly, by an emphasis on "the record" more appropriate to the settling of disputes, the regulations perpetuate a misunderstanding of the

experience with a particular type of reactor. Where the type is standard the board's investigation may be directed more to questions such as quality control than to basic design.

${ }^{78}$ At the risk of offending the lawyer readers, the term should perhaps be explained for the nonlawyer. Official (or, in the case of a court "judicial") notice is the acquisition of information outside the record. "[I]n its broadest sense [it] may be considered to include all methods other than the formal introduction of evidence for informing the court during the course of litigation." J. WEINstein, H. Korn \& A. Miller, New York Crvil Practice, para. 45ir.or, at 45-I74 (I964).

${ }^{79}$ 10 C.F.R. $\$ 2.743$ (i) (1968).

${ }^{80}$ so C.F.R. pt. 2, app. A, para. III(f)(r) (Ig68).

a1 2 K. Davis, Administrative Law Treatise 339 (I958). The importance of the subject to contested issues is obvious, but, if there is to be effective public supervision, it must be dealt with in the case of uncontested issues as well. Chapter 15 of Professor Davis's treatise is an indispensable starting point for a study of this problem.

${ }^{88}$ Io C.F.R. $\$ 2.719, .780$ (1968); ro C.F.R. pt. 2, app. A, para. V(c) (rg68).

${ }^{83} I d$. These restrictions were endorsed by the little Mitchell Panel as necessary to preserve the integrity of the process. $1967 / C A E$ Hearings 475. Such restrictions seem to confuse the purpose of the ex parte rules, to avoid undue influence, with the need to make clear the basis of a finding of fact. 
nature of the board's function. In a proceeding to test the safety of a reactor much of the information on which the judgment is based will be "noticed." Indeed, implicit in the notion of a technical review is that those making the decisions will base it not only on the "record" adduced by the parties but on other information, and on their own "inseparable mixture of information and experience." is the objective, the traditional limitations on the kinds of facts which can be noticed would seem irrelevant. Nevertheless, the requirements of fairness and the objective of adequately informing the public must be satisfied, and this cannot be done unless the source and basis of important assumptions are made clear. ${ }^{85}$

\section{ConcLusion}

The final definition of an appropriate function and method of procedure for the boards will require considerably more study and experimentation. Clearly a great deal more thought must be given to the process of decision making in a matter of this kind. ${ }^{86}$ What is necessary is to recognize the nature of the decision being made, the limits of the practicable investigation at this stage of the process, and the need to permit outside scrutiny of the decision, ${ }^{87}$ and then to fashion a procedure in the light of those factors. In all likelihood, many of the techniques developed to decide between contestants in a lawsuit will be inappropriate, ${ }^{88}$ but what will take their place is less obvious. ${ }^{89}$ Terms such as executive or administrative or expert body or legislative $e^{90}$ are frequently used to describe processes alternative to "judicial" processes, but except as they vaguely indicate a different method of gathering facts, I am not sure I know what they mean.

Whatever the process, methods must be devised for ensuring that all relevant facts are brought out and that competing points of view are aired, and it may be

\footnotetext{
${ }^{84} 2 \mathrm{~K}$. Davis, stspra note 80, at 339 . The fact that the issue is "contested" does not, as noted above, change the nature of the inquiry.

${ }^{85}$ There are obvious limitations as to how far one should carry the principle. Presumably some information is so basic and agreed upon that to require its recitation would be unreasonable.

${ }^{80}$ A good beginning, but directed to judicial rather than administrative procecaings, is Korn, Law, Fact and Science in the Courts, 66 Conum. L. Rev. Io80 (1966).

${ }^{87}$ One suggested answer to the problem of public scrutiny is to make the burden of proof on the applicant "more substantial." Green, supra note 25, at 655. While I would agree that too much of the basis of the decision is "obscured from public vision," I do not see how Professor Green's suggestion would help.

${ }^{88}$ The over-reliance of administrative agencies on "judicial techniques" in deciding questions of all kinds has been criticized by many persons and groups including President Kennedy, Dean Landis, the Senate Judiciary Committee, and the American Bar Association. See the various citations in Gellhorn, note 88 infra, and S. REP. No. 1677 , stipra note 48 , at 67 . As the latter report indicatcs, it was very much on the mind of the JCAE in establishing the boards. Very little attention has been paid to the nature of the processes which are to be substituted.

${ }^{88}$ Professor Walter Gellhorn has suggested that the administrative investigation using nonjudicial techniques be held first and that the tentative conclusions, with factual policy and legal bases clcarly stated, then be exposed to scrutiny. Gellhorn, Administrative Procedure Reform: Hardy Perennial, $4^{8}$ A.B.A.J. 243 ( 1962$)$.

${ }^{\circ 0}$ See, e.g., Organization and Procedures Survey of the Interstate Commerce Commission, a report prepared by the management consulting firm of Booz, Allen \& Hamilton for the Bureau of the Budget.
} 
that some elements of the judicial process should deliberately be introduced to that end. ${ }^{91}$ Scientists' decisions are frequently wrong; and even "executive" processes are fallible-Ford did, after all, produce the Edsel. It is to be hoped that all specialities-lawyers, scientists, and management engineers-will cooperate in fashioning the needed procedures. It seems likely that the experience gained will be useful not only in the realm of reactor licensing but also in other areas where safety or other scientific questions are at issue.

\footnotetext{
${ }^{01}$ One experiment which I would like to see tried is the infusion of some elements of the adversary system into nonjudicial processes. Cf. Fuller, The Adversary System, in Talks on Amertcan Law (Berman ed. 196I); Murphy, Law and Research Supported by Government, in Law aNd the Social Role of Science (Jones ed. I966). The suggestion is usually received less than enthusiastically. In the case of the boards, it has been suggested that the staff act as "devil's advocate," rather than as a supporter of the application. Green, supra note 25, at 656 . Although I would like to see something of that sort tried, I would think that the staff would not be the proper agency to perform that function.
} 